\title{
Congresso de Leitura do Brasil: projetos e demandas para a formação de leitores ${ }^{1}$
}

\section{Brazilian Reading Congress: projects and demands for readers' education}

https://doi.org/10.34112/2317-0972a2020v38n79p75-90

GenianA Dos SANTOS ${ }^{2}$

RESUMO: Este trabalho apresenta a constituição do Congresso de Leitura do Brasil em um cenário de disputas e negociação por projetos de formação de leitores. Nesta discussão, destaca-se a contribuição do COLE como espaço de produção de conhecimento sobre a formação de leitores, algo que fortalece a formação inicial para a docência. Trata-se de uma pesquisa qualitativa, bibliográfica e documental, que considera os contextos de disputa, antagonismo e articulação em prol de uma política de formação de leitores. Como resultado é possível afirmar que o COLE formaliza a constituição de uma comunidade epistêmica e de algumas comunidades disciplinares que atuam como contexto de influência na produção das políticas educacionais voltadas à leitura, ao passo que modificam o âmbito da formação inicial de professores/formadores de leitores por meio de suas práticas discursivas/pedagógicas. Nesse sentido, o COLE se diferencia por ser um espaço potencialmente democrático para produção curricular dos cursos de Letras e Pedagogia, fortalecendo o objeto de estudo leitura no campo da pesquisa educacional.

Palavras-chave: COLE; política de leitura; política de currículo; discurso.

1. Originado da pesquisa de Doutorado “O meu aluno não lê”: sentidos de crise nas políticas curriculares para a formação em leitura, defendida no Programa de Pós-Graduação em Educação da Universidade do Estado do Rio de Janeiro, 2017.

2. Universidade Federal de Mato Grosso, Cuiabá, Mato Grosso, Brasil. 
ABStRACt: This paper presents the constitution of the Reading Congress of Brazil in a disputes and negotiation scenario related to projects for readers' education. In this discussion, the contribution of the Brazilian Reading Congress (COLE) stands out as a space for the production of knowledge about the education of readers, something that strengthens the initial training for teaching. It is a qualitative, bibliographic and documentary research, which considers the contexts of dispute, antagonism and articulation in favor of a policy of readers' education. Thus, it is possible to state that COLE formalizes the constitution of an epistemic community and of some disciplinary communities that act as a context of influence in the production of educational policies aimed at reading, while modifying the scope of training of teachers / trainers of readers through their discursive / pedagogical practices. In this sense, COLE is different because it is a potentially democratic space for courses curricular production of Letters and Pedagogy, strengthening the object of study "reading" in the field of educational research.

KEYWORDS: COLE; reading policy; curriculum policy; speech.

\section{INTRODUÇÃO}

A escola, instituição formal de aprendizagem, tem destinado às disciplinas de Língua Portuguesa e de Literatura a responsabilidade por mediar, a partir do ensino da leitura, a aprendizagem das mais diversas formas de conhecimento, condicionando a qualidade educacional à formação leitora. Em termos de organização curricular isso se materializa nas falas dos professores sobre a capacidade de ler e compreender, mas também na organização e distribuição de carga horária para cada componente curricular no decorrer da educação básica.

Esse entendimento se ancora na perspectiva de que a leitura possui natureza transversal, se relaciona à cultura de valorização do escrito e, portanto, não se circunscreve a um conhecimento disciplinar alocado em um dado componente pedagógico, pois ao passo que se constitui como um modo de conhecer, também é uma forma de praticar a cultura.

O cenário de decisão curricular possui impacto direto no seu próprio campo, uma vez que opera no sentido de fortalecer um discurso de crise da escola, principalmente pública, e, sobretudo, de crise leitora sem precedentes (SANTOS, 2017; 2019). Trata-se de um antagonismo que mobiliza o enfrentamento da crise enunciada por meio de práticas articulatórias amplas, significadas pela ideia de comunidade epistêmica (DIAS, 2006), e que enfatiza a disputa e a negociação 
por projetos específicos de formação de leitores, encampados pelo pedagogo ou pelo letrado em uma lógica disciplinar.

Nesta discussão, focalizam-se as concepções de leitura e projetos de formação de leitores propostos no âmbito do Congresso de Leitura do Brasil (COLE) a partir de sua constituição e trajetória. Desse modo, salienta-se que, como espaço discursivo, as produções dispostas pelo COLE contribuíram para a ressignificação do ensino no cenário educacional brasileiro, de modo a impactar a mudança de paradigmas educacionais e, mais estritamente, à construção curricular de cursos ligados à formação de leitores escolares (Letras e Pedagogia).

O presente estudo foi desenvolvido no campo de investigação sobre currículo, sustenta-se na compreensão de currículo pela via da política cultural (LOPES, 2019) e focaliza significações produzidas no âmbito do Congresso de Leitura do Brasil como potencializadoras para formação de leitores, mas, sobretudo, para o campo das políticas curriculares de leitura em que comunidades epistêmicas e disciplinares disputam/assumem projetos de formação leitora.

Em comunidades epistêmicas destacam-se sujeitos que se identificam por um determinado conhecimento e por diferentes ações que são capazes de constituir um contexto de influência. Segundo Ortiz (2010), as comunidades epistêmicas são formadas por experts, funcionários públicos, professores, administradores, profissionais de relações públicas, assessores de imagem, assessores e conselheiros políticos e por mais uma pluralidade de sujeitos. Tais pessoas, em um determinado momento e por estarem investidas de uma relação saber/poder, traduzem o que seria a verdade curricular em práticas pedagógicas escolares, por estarem pautadas na ideia de tradição, estabelecendo fundamentos para formação dos seres humanos. Sobre isso, Bhabha (2013, p. 21) destaca que "[...] o reconhecimento que a tradição outorga é uma forma parcial de identificação”. Essa identificação com o verdadeiro/tradição/fundamento impulsiona a luta por significação na arena de disputas curriculares.

Já as comunidades disciplinares estão circunscritas a um determinado campo de saber, aparentemente seus interesses são mobilizados em face de demandas ${ }^{3}$ muito particulares para o grupo disciplinar produzindo identificação muito menor em um grupo. Desta forma, os sujeitos podem dissipar a articulação em torno de

3. O conceito de demanda é entendido, no presente trabalho, enquanto unidade mínima de significação política, e possibilita assim processos de identificação e articulação entre diferenças. Este específico sentido do termo é desenvolvido na teoria do discurso proposta por Ernesto Laclau (2011; 2013), se ancora nos conceitos psicanalíticos que relacionam demanda/necessidade e predisposição à ação, enquanto emergência do sujeito. 
uma demanda pela ausência de identificação com ela. As problemáticas de uma comunidade disciplinar parecem ser muito mais contextualizadas no interior das próprias disciplinas, da escola, da universidade, por exemplo.

Na busca por evidenciar a trajetória de constituição do COLE como um espaço de negociação em face da crise da leitura/crise educacional, recorreu-se à Teoria Política do Discurso (TPD) de Ernesto Laclau (2011; 2013) e à perspectiva discursiva desenvolvida por Lopes (2011; 2015; 2017; 2019). O estudo se inscreve em um universo de pesquisa mais amplo e se alinha às investigações desenvolvidas pelo grupo de pesquisa Currículo: sujeitos, conhecimento e cultura (UERJ), faz parte de um conjunto de reflexões disposto no estudo de doutoramento denominado Meu aluno não lê: sentidos de crise nas políticas curriculares para a formação em leitura, o qual privilegiou o COLE (1978-2014) como material empírico.

O referido trabalho tomou como instância de significação a produção bibliográfica (2004-2014) disposta na Biblioteca Digital Brasileira de Teses e Dissertações (BDTD) sobre leitura e formação de leitores para as etapas da educação básica (educação infantil, ensino fundamental e ensino médio) e a produção documental organizada pela Associação de Leitura do Brasil (ALB) sobre o COLE entre o período supramencionado.

Os critérios adotados pela pesquisa qualitativa deveriam abarcar um conjunto de expressões e sentidos (MINAYO; DESLANDES; GOMES, 1994), próprios do processo de negociação, salutar à construção de políticas potencialmente democráticas sobre leitura e formação de leitores, e, para tal, são de cunho descritivo e exploratório. Este trabalho está estruturado a partir de eixos por meio dos quais serão apresentadas reflexões acerca da trajetória constitutiva do COLE como um espaço de produção de Políticas Curriculares, sendo eles: (1) COLE - Constituição e Trajetória; (2) Teoria Política do Discurso e Perspectiva Discursiva; (3) COLE e seus impactos como contexto de influência - algumas considerações.

\section{COlE - Constituição e trajetória}

Poucos estudos têm se dedicado a delinear a constituição, trajetória e impactos do COLE como um contexto de influência para o ensino da leitura e formação de leitores escolares. Nesse sentido, evidencia-se esse espaço discursivo como de fundamental relevância para a construção de políticas curriculares com vistas à política cultural de formação leitora. Além disso, é preciso reconhecer que o COLE propiciou um 
contexto de influência (BALL e BOWE, 1992) na produção de projetos de formação de leitores, pois o evento reúne os principais ícones do ensino da leitura no país.

O Congresso de leitura é um evento produzido pela Faculdade de Educação da Unicamp desde 1978 , possui abrangência nacional e está na sua $22^{\circ}$ edição. Trata-se de um evento que possui caráter científico-acadêmico-cultural, mas também político. Em sua história, é possível identificar diversas demandas, articulações e projetos de formação de leitores, algo que o configura como espaço de disputa e negociação.

Conforme Oliveira (2015), o início do $\mathrm{COLE}^{4}$ (1978) se deve à estratégia de articulação entre o Departamento de Metodologia de Ensino da Faculdade de Educação da Unicamp, o Centro de Leitura (CELE), Bibliotecários e a Feira do Livro. Ainda que fosse necessária a utilização da estrutura da Feir's do Livro, essa estratégia buscava, a partir da proposição de um espaço comunitário e formativo sobre a leitura, subverter o perfil mercadológico, imprimindo um perfil pedagógico e de fortalecimento coletivo ao evento. Essa primeira configuração destacou a demanda por acesso ao objeto livro, não restrita a compra de livros, mas envolta em um contexto de luta por educação em um período de censura.

Para Quinaglia (2006) o evento estava inserido em um contexto de mudança sociocultural que constituiu a educação democrática enquanto uma bandeira urgente que deveria ser defendida ativamente por uma militância. Nesse sentido, relevante se faz destacar que no COLE são apresentados textos imprescindíveis para a mudança do paradigma educacional sobre o ensino tradicional e novas formas de ensinar a partir de Freire, Geraldi, Silva, Mortatti e Zilberman, cada um desses trabalhos representava e aglutinava demandas singulares, porém articuladas para a superação da crise leitora.

Observa-se assim, objetivo comum condensado dirigido à democratização. Esta confluência, em oposição à repressão, está presente desde a primeira edição do evento, assim como a acepção da leitura enquanto prática cultural. Tal ideário possibilitou a formação de uma comunidade de ensino e democratização da leitura, que opera de modo a aproximar o objeto livro à realidade escolar. A partir de estudos sobre esse período do COLE, é possível compreender que diferentes atores, não necessariamente professores, participaram deste trabalho. Tal constatação,

4. Para realização deste trabalho foram acessados os arquivos digitais das ALB. Disponível em: http:// alb3oanoslinhadotempo.blogspot.com/.

5. Com o intuito de situar o leitor, os anos correspondentes às referidas edições dos COLEs citados são indicados entre parênteses. 
possibilita afirmar que esse período de articulação possibilitou a constituição de uma comunidade epistêmica em prol da leitura.

Essa série de movimentos foi resultado de um jogo de forças organizado em uma conjuntura do particular contexto político brasileiro do período focalizado nesta pesquisa. $\mathrm{O}$ desejo amplamente compartilhado pela democratização expôos um contingente que reage à insatisfação em relação à uma atuação política democrática efetiva, impedida, em larga medida, durante a ditadura militar brasileira. Um vetor correspondente ao vácuo criado pela ausência - ou profundo enfraquecimento - da dimensão democrática tornou plausível uma consonância de demandas, o que resultou em uma nova articulação, e assim, extravasou uma possível perspectiva política única e central. Tal configuração marcou a estruturação do COLE e permanece até as suas edições mais recentes; sela o evento enquanto reação à uma realidade ambivalente que se mostra, em muitos aspectos, adversa, e, em outros, intensamente resiliente.

Este fenômeno de esvaziamento do significante - no caso particular do contexto estudado, dado ao sentido prático da democracia, na condição do conjunto de exercícios que evoca - tem a sua potência articuladora apontada por Laclau (1989; 2011). O significante vazio é um elemento capaz de estabilizar as diferenças, visto que representa um ideal maior, e põe em suspensão interesses menores ou demandas particulares. Na teoria do discurso, é dado como um dispositivo analítico de força política, devido a sua capacidade de provocar articulação. Nesse sentido, tais articulações são criadas no bojo de um movimento reativo, que se deve, majoritariamente, ao esforço de responder demandas frustradas (LOPES e MENDONÇA, 2013), necessariamente imbricadas nos processos de mudança e inquietação política vivenciados no período.

Assim, o cenário descrito fornece ao $2^{\circ} \operatorname{COLE}$ (1979) elementos que viabilizam a estruturação de movimento articulatório com vistas à hegemonização de uma proposta pedagógica para o ensino da leitura. Essa edição do evento foi denominada "Pedagogia da Leitura". Porém, as possibilidades das articulações, que apresentavam com uma maior força nesse momento, propiciaram a eclosão de outros projetos, um deles foi a proposta de criação de uma revista. Oliveira (2015) assinala que no intento de formalizar uma linha de publicação especializada em leitura, a Revista Teoria e Prática foi criada, sendo ela "[...] uma rede de conversas em torno da leitura" (SILVA, SILVA, OLIVEIRA, 2018, p. 12). Nos anos seguintes, para estruturação maior do evento e da revista, bem como de uma rede de pesquisadores associados, a ALB foi criada.

No que tange à contribuição da Revista para a estruturação de um pensar sobre a leitura, destaca-se que é único periódico do país dedicado especialmente a 
temática leitura, “[...] subsidiando o processo de formação inicial e continuada de professores e estimulando a produção de políticas públicas relacionadas ao livro, ao leitor e à leitura" (SILVA, SILVA, OLIVEIRA, 2018, p. 12). O efeito produzido pela publicação contribuiu para oferecer um novo ferramental desses profissionais, que seriam os principais vetores para a expansão do processo que a revista contribuía;

[...] os leitores encontraram ou foram encontrados por essas vozes e, pela leitura, as movimentaram e as penetraram de muitas formas, a partir de múltiplos lugares, sendo também por elas penetrados. Pela leitura, as habitaram, assimilaram, reestruturaram e modificaram.... Delas fizeram diferentes usos, sendo praticantes em sua vontade histórica de existir (SILVA; SILVA, OLIVEIRA, 2018, p. 11).

No $3^{\circ}$ COLE (1981) outros sujeitos foram conclamados a lutar pela leitura, ameaçada pela sua ausência no contexto familiar. Condensar a leitura como atividade corriqueira, familiar e íntima parece que foi uma das proposições dessa edição do evento. Sobre essa questão, destaca-se um deslizamento em que o antagonismo à leitura é encarnado pela censura; posteriormente, pela ausência pedagógica; e, no $3^{\circ}$ COLE pela televisão que toma o lugar da leitura no contexto familiar. Esse movimento é comum à construção de articulação política, pois consiste em uma atualização do processo de articulação que, ao se ampliar, possibilita o fortalecimento da cadeia articulatória em prol da leitura.

Como parte do processo de expansão do COLE, em sua $4^{\circ}$ edição (1983), os professores de Educação Básica passaram a inscrever trabalhos, tal movimento expressou a ideia que ilustrou essa edição do evento: "Leitura na Sociedade Democrática: do discurso à ação”. Enquanto movimento articulatório, correspondeu não somente a possibilidade de maior abrangência das discussões, mas a uma responsabilização social pela democratização da leitura. Contudo, o direcionamento ao professor atualizou a cadeia de articulação, e definiu uma identidade educacional para o evento.

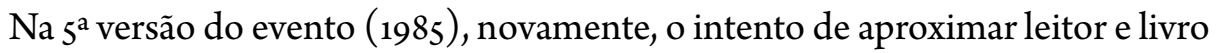
ficou em destaque. A articulação inicial ganhou novos pontos, além relevância dos professores, como nos primeiros momentos, contou também com bibliotecários. Regina Zilberman encampou discussões sobre as políticas de acesso ao livro, ganhou destaque, nesse momento, o sistema educacional e as responsabilidades governamentais. As bibliotecas e as políticas de formação leitora foram temas expressos nesse momento discursivo (OLIVEIRA, 2015). 
Nos anos seguintes, após a abertura democrática, as discussões se voltaram aos métodos de ensino da leitura, orientando a escola para o cumprimento do seu papel de instituição promotora da leitura. Ainda que muitas temáticas tenham sido discutidas, permaneceu a preocupação pedagógica e a tentativa de sistematização de um saber metodológico para o ensino da leitura e sua universalização - até o $6^{\circ}$ COLE (1987).

No $7^{\circ}$ COLE (1989), denominado "Nas malhas da leitura: puxando outros fios”, a expressão de significações mais plurais de leitura se evidencia a partir de uma ressignificação do conceito de texto orientava a mudança do ensino de língua portuguesa. Essa edição do evento indicava maior proximidade com as discussões do campo disciplinar da linguagem, que muito se relacionava à necessidade de superar o ensino gramatical fora de uma unidade de sentido, fora do texto. A esse respeito, embora o evento sinalizasse para inúmeras possibilidades pedagógicas, a leitura passa a ser focalizada como um meio de viabilizar a transformação social.

$\mathrm{Na}$ "Fala de abertura" do $7^{\circ}$. COLE, em 1989, o então presidente da ALB, João Wanderley Geraldi, assim justifica a necessidade de se "puxarem outros fios", nas "malhas da leitura", em consonância com as especificidades do contexto histórico: Este nosso $7^{\circ}$. Congresso, realizado no contexto de um tempo difícil, coincide também com um tempo de enfrentamento de desafios: de concretizar sonhos, de decidir políticas, de praticar mudanças. E vivemos em misérias públicas do analfabetismo, de pobreza, de fome, queremos viver também o direito, para a grande maioria de nós pela vez primeira, de escolha e de decisão entre caminhos alternativos a seguir na construção da sociedade brasileira. Um direito da cidadania conquistada a duras penas. E a ele, outros direitos, muitos, a conquistar e, mesmo, a descobrir. "NAS MALHAS DA LEITURA, PUXANDO OTUROS FIOS” há de enfrentar a distância entre a realidade de um país [...] e o sonho da leitura como uma prática social possível a todos os brasileiros. No intervalo entre sonho e realidade, a ação possível vem tornando possível o impossível [...] Este é o porquê deste congresso tentar trazer para dentro da pesquisa acadêmica ou para dentro da prática pedagógica a visão daqueles que fazem da produção do que se lê o seu cotidiano, produção que não se limita ao texto verbal, mas que coloca, a cada dia, diferentes objetos de leitura (MAGNANI 2009 citando GERALDI, 1991, p. 10). 
Na edição intitulada "Leitura: autonomia, trabalho e cidadania", correspondente ao $8^{\circ} \mathrm{COLE}^{6}$, ocorrida em 1991, a ALB era presidida por Ezequiel Theodoro da Silva. Maria do Rosário Mortatti Magnani e José Carlos Libâneo, Affonso Romano de Sant'Anna, Wanderley Geraldi e Ana Luiza Bustamente Smolka eram alguns nomes de destaque nas apresentações de mesas redondas. Nas conferências, dirigidas especificamente à relação entre literatura e educação, houve destaque para Moacir Scliar, médico e escritor, falecido em 2011, e Affonso Romano de Sant'Anna, que conduziram uma discussão acerca da necessidade da presença da literatura na vida dos educadores (ANAIS, 8० COLE, 1991).

Nessa edição do evento, pode-se interpretar que as proposituras cessaram de reunir os sentidos costumeiramente veiculados à leitura. Nesse sentido, valor estético, obras literárias anteriormente expostos perderam espaço no material de divulgação do evento. No que tange à Feira do Livro, ela continuava a insistir nos sentidos mais tradicionalmente destacados pelo COLE. Ainda nessa oitava edição, a leitura passou a ser relacionada com significados da luta política, como sugeriram os termos "trabalho e cidadania”. Esta dupla perspectiva foi responsável por um alargamento das possíveis imagens atribuídas ao leitor; a mulher passou a ser representada enquanto leitora pela primeira vez nos materiais de divulgação do evento, visto que anteriormente, somente o gênero masculino era representado nas situações de leitura.

No que diz respeito aos nomes das atividades propostas, há que se considerar a recorrência da expressão prática de leitura, destacada nas formas de apresentação das atividades dessa edição do evento como um retorno aos primeiros anos do COLE. No discurso de abertura, Ezequiel Theodoro da Silva (1991, s/p. $)^{7}$, salienta que o " [...] $8^{\circ}$ COLE registra e destaca mais de 200 pessoas cujo fazer histórico, em termos de direção da consciência e da preocupação, é praticar, é viver projetos na esfera da educação de leitores". Acerca disso, é possível entender que o conjunto significante de temas, arregimentados pelos participantes e seus trabalhos, estava intimamente relacionado à prática de ensino, com uma orientação pedagógica com vistas à qualidade educacional, via formação de professores leitores.

As possibilidades de práticas de leitura pelos professores constituem a essência deste congresso. Essa preocupação tem a sua razão de ser à medida em que uma mudança

6. Fonte: https://issuu.com/pesquisaalbmemorias/docs $/ 8$ cole_-_anais_baixaresolucao. Acesso em: 10/01/2017.

7. Para realização deste trabalho foram acessados os arquivos digitais das ALB: https://issuu.com/ pesquisaalbmemorias/docs $/ 8$ cole_-_anais_baixaresolucao. 
ou avanço da educação escolarizada deste país depende fundamentalmente do repertório de conhecimentos dos professores (ANAIS, $8^{\circ}$ COLE, SILVA, 1991, s/p.)

Este tencionar das práticas discursivas revela diferentes projetos de formação de leitores entre as comunidades epistêmicas: pedagógica, literária, letrada, todos orientados pela ideia de prática. Em uma das falas da referida edição - para um exemplo in loco - encontramos: "O 'retorno à prática' é incontrolável por qualquer congresso científico. Porém fundamentados no pleno êxito deste $8^{\circ} \mathrm{COLE}$, podemos avançar na hipótese de que as relações entre a leitura e a qualidade do ensino serão criticamente refletidas daqui para frente" (ANAIS, 8 COLE, 1991, p. 33).

Todas as mesas redondas propostas para a abertura das atividades tinham o professor como o foco. Isso pode ser compreendido a partir da proposta denominada "A prática de leitura do professor brasileiro: análise e perspectiva", discutida por Maria do Rosário Mortatti Magnani, bem como por Ana Maria Sanchez esta mediante interpretação da revista Nova Escola. O tema "professor e a leitura crítica", discutido por José Carlos Libâneo, abordou as funções da escola, a metodologia dos conteúdos e os conhecimentos relevantes para a transformação da sociedade, além de destacar a importância da leitura em tal processo (ANAIS, $8^{\circ}$ COLE, 1991). A presença desses autores desvelou uma possibilidade de articulação entre as diferentes comunidades disciplinares em prol da formação de leitores.

Os índices de aprendizagem e leitura a partir da comparação com países desenvolvidos, e os modos como são alcançados, também são elementos que possibilitam a articulação de diferentes projetos de formação de leitores. Ademais, os problemas educacionais e os protestos são expressos por meio de moções, realçando a falta de estrutura das escolas brasileiras, a ausência de apoio à categoria docente, em particular, no que tange à realização das greves e a ausência das personalidades políticas na construção do diálogo (ANAIS, $8^{\circ}$ COLE, 1991).

A discussão acerca da democracia continuou a ser tematizada no $9^{\circ} \mathrm{COLE}^{8}$ (1993) por Luiz Percival Leme Brito. Acerca disso, existiu uma tentativa em retomar a orientação para os temas democratização e luta pelo ensino e pela transformação social em prol da cidadania, postulados nas primeiras edições do evento. Essa focalização no professor e na pluralidade metodológica capaz de formar leitores foi suspensa para se privilegiar a militância mais ampla por inserção social.

8. Fonte: http://alb.org.br/arquivo-morto/edicoes_anteriores/anais13/arquivos/intro.swf. Acesso em: 03/01/2017. 
Quanto a inserção social, também tematizada na edição anterior do evento, mediante o Programa salas de leitura, a formação dos professores para a promoção de leitura não deixou de ser apontada. Ela, além de ser expressão de uma política, esboçou um método, um espaço e possíveis agentes responsáveis pela formação leitora. $\mathrm{O}$ enfoque que o $9^{\circ} \mathrm{COLE}$ indicou uma tensão em face das alternâncias de demandas para a formação de leitores, que ora foram direcionadas à mudança social mais ampla, ora se mostraram mais comprometidas com a realidade cotidiana da escola e sua forma de modificar as condições de leitura entre os estudantes.

O $10^{\circ}(1995)$ e no $11^{\circ}$ COLE (1997), respectivamente afigurados de "Leitura e Sociedade" e de "A voz e a letra dos excluídos", embora se relacionarem às discussões das $8^{\mathrm{a}}$ e $9^{\mathrm{a}}$ edições do evento, salientaram reinvindicações menos específicas em relação ao ensino e à aprendizagem escolar. Nesse sentido, o campo da arte se faz presente enquanto forma disciplinar da leitura, e, apresenta-se na opção radical pelo rompimento com o que está circunscrito no contexto didático, da disciplina literária ou ainda das essencializações expostas nas edições anteriores.

A Feira do Livro nesse período foi renomeada como " $1^{\circ}$ Feira de Leitura e Arte”, com utilização da mesma imagem da capa dos anais, o que traz uma marca disciplinar para o evento. Essa modificação na forma de nomear a feira indica a ressignificação de alguns sentidos, como a focalização na ação da leitura, especificamente a literária, em contraponto ao objeto de leitura, materializado pelo livro. Isso consistiu ainda em uma tentativa de aproximação entre feira do livro e evento, algo que não se sustentou na trajetória do COLE.

As edições dos eventos apresentam demandas importantes que se perpetuam até a atualidade. Embora dispostas em eventos diferentes, elas se hibridizaram, e recolocaram a leitura na condição de ato promotor de igualdade, associado à possibilidade de rompimento com as condições de exclusão. De certo modo, tal articulação respondeu pela centralização da escola como instituição que tende, de forma privilegiada, a possibilitar a democracia e a inclusão social.

Em uma política de leitura, expressa tanto nos documentos oficiais quanto nas produções acadêmicas, essa articulação também se destaca. A tensão anteriormente problematizada, em que a alternância entre a centralização dos métodos de leitura ou a centralização da leitura para inclusão, aparentemente se apagou. A transformação social e a luta são destacadas como demandas a serem articuladas aos espaços e situações educacionais, do mesmo modo que os objetos de leitura. Tais temáticas parecem sustentar um âmbito de enfrentamento e de socialização 
de conhecimento esboçado em todas as edições do evento, mas são expressas de modo mais patente no $10^{\circ} \operatorname{COLE}(1995)$.

$\mathrm{O} 11^{\circ} \mathrm{COLE}$ (1997) destacou a radicalidade dessa mudança nos sentidos projetados pelo evento. Com o nome "A voz e a letra dos excluídos", o caderno de resumos traz a imagem de uma criança com o rosto parcialmente coberto e, ao fundo, uma paisagem que remete a um aterro sanitário. A figuração de uma situação degradante sugere a necessidade de organização de uma militância por parte da sociedade e, mais especificamente, dos educadores, e, enquanto demanda, se atrela ao significado social mais amplo de defesa de direitos. A leitura, nesse contexto, foi vista de outro modo, e assim, posta como aquela que pode barrar processos de exclusão, principalmente na infância, operacionalizada pela função de obstruir de um mal maior.

O trabalho e a exploração infantil foram as temáticas de destaque, embora a leitura não esteja como eixo central das discussões, há uma interpretação que aponta a leitura como elemento de pré-condição para a possibilidade de transformação. Talvez devido a diferença entre demandas dessa edição e das anteriores com um distanciamento do objeto leitura, o $12^{\circ} \mathrm{COLE}$ (1999) se definiu tão radicalmente como um evento sobre leitura, práticas de leitura, modos de ler, leitores e suas leituras, com uma ampla articulação, que restringiu temáticas que não estivessem estritamente relacionadas à temática que sempre constituiu a centralidade do evento.

\section{Teoria Política do Discurso e Perspectiva Discursiva}

A Teoria Política do Discurso (TPD) foi proposta por Ernesto Laclau (1989; 2011), ela oportuniza pensar o pensar sociológico em termos discursivos e a articulação como condição de possibilidade para a construção política democrática. Trata-se de uma teoria discursiva que se origina das reflexões culturais a partir de aspectos da filosofia da linguagem, psicanálise lacaniana e teoria política. A TPD é utilizada neste trabalho para a interpretação dos processos de constituição do COLE, suas demandas, contexto e antagonismo/ameaça, além dos processos articulatórios e suas diferenças. No presente estudo, em específico, são focalizadas as noções de Democracia, Significante Vazio, Demanda e Articulação. Operadores analíticos que não possuem uma ordem pré-determinada ou hierarquia e podem ser focalizados independentemente, contudo, neste estudo, são tomados como elementos de uma dinâmica discursiva.

Com o tempo, o COLE alternou suas demandas e projetos de formação leitora, em direção a uma ampliação do campo educacional ou uma restrição ao campo 
da linguagem ou do literário, algo que evidencia um contexto de negociação e tensionamentos. A democracia e o acesso consistiram em elementos aglutinadores de toda ordem de reivindicações nesse espaço, possibilitando assim a ampliação da cadeia articulatória.

Neste estudo, destaca-se que houve um esvaziamento do conceito de democracia entre 1978-1983, torna-se um significante vazio. Este fenômeno possibilitou a associação de diferentes agentes tais como instituições, agrupamentos de pessoas e a organização da feira do livro, que suspenderam suas diferenças e interesses particulares em nome de uma luta comum pela democracia e, como corolário, por acesso democrático da leitura. Democracia apresentava uma pluralidade de sentidos - suspensos, no momento de articulação política -; acesso, liberdade, aprendizagem, transformação, possibilitando que diferentes formas de pensar - e articular - o substantivo democracia.

Em relação às demandas e projetos de formação de leitores, é importante frisar que o COLE sempre esteve entre um projeto de formação de professores e um projeto de formação de leitores escolares, e, nesse sentido, avaliando o alcance das produções apresentadas no evento, bem como a mudança de práticas escolares de ensino da leitura, logrou êxito em seus propósitos, visto que sustentou a ideia de uma prática de leitura/cultural como necessária à prática de ensino da leitura.

A simultaneidade de comunidades epistêmicas e tendências pedagógicas também estiveram presentes no evento, que tencionavam ideários distintos de formação, foi importante para a defesa de uma escola plural para a formação de leitores em diferentes momentos do COLE. Tal ponderação é salutar para não diminuir a contribuição de comunidades disciplinares que deram identidade ao COLE. Contudo, em tempos de múltiplas possibilidades de leitura e articulações improváveis, uma identidade fixa, com projetos de leitura mais restritos, pode, do mesmo modo que definiu o COLE, fazê-lo definhar.

COLE E SEUS IMPACTOS COMO CONTEXTO DE INFLUÊNCIA - ALGUMAS CONSIDERAÇÕES

Este trabalho apresentou fragmentos da história do Congresso de Leitura do Brasil com vistas a destacar a sua grande importância para o campo das políticas curriculares de leitura. A partir de sua história, enfatizou-se as demandas e projetos 
de formação de leitores entre $\mathrm{o} 1^{\circ}$ e $\mathrm{o} 12^{\circ} \mathrm{COLE}$, quando a prática de leitura retorna enquanto uma demanda a ser defendida por todos, como nos primeiros COLE.

A partir da interpretação dos documentos relativos ao evento, procurou-se apresentar as ideias centrais veiculadas nas edições, mapeando assim sentidos em disputas sobre leitura e formação de leitores. Os fragmentos apresentados permitem a reflexão sobre uma alternância entre demandas mais amplas, possibilitadas por uma lacuna, um vazio, espaço no qual a articulação de diferentes sujeitos da política, e outros mais específicos pertencentes ao campo disciplinar, conferindo assim identidade para o evento (literária, didático pedagógica, linguística).

Destarte, o próprio processo de alternância mencionado permite inferir que ao longo dos anos, e principalmente no período ora destacado, além de ter impactado positivamente o currículo com diferentes demandas e projetos de formação leitora, o COLE se constituiu como um espaço democrático de produção de políticas curriculares de formação de leitores.

\section{REFERÊNCIAS}

BALL, S; BOWE, R. Subject departments and the "implementation" of National Curriculum policy: an overview of the issues. Journal of Curriculum Studies, Londres, v. 24, n. 2, p. 97-115, 1992.

BHABHA, H. K. O local da cultura. Belo Horizonte: Editora da UFMG, 2013.

CONGRESSO DE LEITURA DO BRASIL, Unicamp, Campinas. Resumos $3^{\circ}$ Congresso de Leitura do Brasil. Campinas (1981). Disponível em: https://issuu.com/pesquisaalbmemorias/docs/3 cole_-_resumos. Acesso em: dezembro de 2016.

CONGRESSO DE LEITURA DO BRASIL, Unicamp, Campinas. Tempo de COLE. Disponível em: https://issuu.com/pesquisaalbmemorias/docs/catalogotempocole_2014. Acesso em: janeiro de 2017.

DIAS, R. E. ; LÓPEZ, S. B. Conhecimento, interesse e poder na produção de políticas curriculares. Currículo sem Fronteiras, v. 6, n. 2, p. 53-66, jul./dez. 2006. Disponível em: www. curriculosemfronteiras.org. Acesso em: 05 jan. 2015.

LACLAU, E. Emancipação e Diferença. Rio de Janeiro: EdUERJ, 2011.

LACLAU, E. A razão populista. Tradução Carlos Eugênio Marcondes de Moura. São Paulo: Três Estrelas, 2013.

LOPES, A. C. Discurso nas políticas de currículo. Rio de Janeiro: Faperj, 2011.

LOPES, A. C. Normatividade e intervenção política: em defesa de um investimento radical. In: LACLAU, E ; MENDONÇA, D. (Org.). A Teoria do Discurso de Ernesto Laclau: ensaios críticos e entrevistas. São Paulo: Annablume, 2015. p. 117-147.

LOPES, A. C. Teorias pós-crítica, política e currículo. Educação, Sociedade \& Culturas, Porto, n. 39, p. 7-23, 2013. 
LOPES, A. C. Itinerários formativos na BNCC do Ensino Médio: identificações docentes e projetos de vida juvenis. Revista Retratos da Escola, Brasília, v. 13, n. 25, p. 59-75, jan./maio 2019. DOI: http://dx.doi.org/10.22420/rde.v13i25.963.

MAGNANI, M. R. De leis duras ఓ́ noivas voadoras - 30 anos de COLE: temáticas e moções, 2009. Disponível em: http://alb.com.br/arquivo-morto/edicoes_anteriores/anais17/txtcompletos/ conferencias/Maria_Rosario.pdf. Acesso em: 16 out. 2015.

MINAYO, M.; DESLANDES, S. F.; GOMES, R. Pesquisa social: teoria, método e criatividade. Petrópolis, RJ: Editora Vozes, 1994.

OLIVEIRA, L. de S.; SILVA, L. L. M. da. A biblioteca escolar entre as páginas escritas do Congresso de Leitura do Brasil e da Revista Leitura: Teoria \& Prática (de 1978 a 1985). Monografia (Graduação). Licenciatura em Pedagogia, Universidade Estadual de Campinas, Campinas, 2015.

OLIVEIRA, L. de S.; SILVA, L. L. M. da. 1987 - espaços de leitura nas páginas do Congresso de Leitura do Brasil - COLE (1978-1993). Dissertação de Mestrado, Programa de Pós Graduação em Educação-, Universidade Estadual de Campinas, Campinas, SP: [s.n.], 2018.

ORTIZ, J. Comunidades e epistémicas y Políticas Educativas. In: FORO TALLER, POLÍTICAS EDUCATIVAS, UNIVERSIDADE AUTÓNOMA METROPOLITANA, 2010, Xochimilco. Disponível em: https://www.youtube.com/watch?v=IoqlnSgptqE. Acesso em: 20 jan. 2015.

QUINAGLIA, Ivana A. L. A leitura da leitura: o que traz a revista Leitura: Teoria \& Prática sobre teorias e práticas de leitura. Dissertação (Mestrado). Programa de Pós-graduação em Educação, Universidade de Sorocaba, Sorocaba, 2006.

SANTOS, G. Meu aluno não lê: sentidos de crise nas políticas curriculares para a formação em leitura. 2017. 233 f. Tese (Doutorado em Educação) - Universidade do Estado do Rio de Janeiro, Rio de Janeiro, 2017.

SANTOS, G. Políticas curriculares de leitura: crise, antagonismo e negociação no Congresso de Leitura do Brasil (COLE). Curitiba: CRV, 2019.

SILVA, E. T.; SILVA, L. L. M.; OLIVEIRA; L. M. (Org.). Palavras andantes: ensino da leitura antologia comemorativa. Campinas, SP: Edições Leitura Crítica; ALB, 2018.

\section{SOBRE A AUTORA}

Geniana dos Santos é graduada em letras (Universidade Federal de mato Grosso) e pedagogia (Claretiano Centro Universitário), tem Mestrado em Educação (Universidade Federal de Mato Grosso) e Doutorado em Educação (Universidade do Estado do Rio de Janeiro). É professora da Universidade Federal do Mato Grosso. Tem experiência na área de pedagogia e didática, com pesquisa nos seguintes temas: teoria do discurso, políticas curriculares, práticas de linguagem, leitura e didática. Atua no Núcleo de Educação Aberta e a Distância (NEAD) como docente e coordenadora pedagógica do Polo de Canarana. Participa do grupo de pesquisa Políticas de Currículo e Cultura 
Congresso de Leitura do Brasil: projetos e demandas para a formação de leitores

(UERJ); Políticas Contemporâneas de Currículo e Formação Docente (UFMT) e do grupo de pesquisa Políticas de Currículo e Alteridade, da Universidade Federal de Rondonópolis.

E-mail: genianacba@gmail.com.

Orcid: https://orcid.org/oooo-0oo1-6926-0132.

Recebido em 27 de abril de 2020 e aprovado em 29 de junho de 2020. 